\title{
A Proposed Method to Design Specialized Web Pages for Visually Impaired and Blind Students
}

\author{
Yasar Abdul Razak Al-Jaleeli", Anis F. Galimyanov \\ Institute of Computational Mathematics and Information Technologies, Kazan Federal University, Russia
}

Received July 12, 2019; Revised September 20, 2019; Accepted September 27, 2019

Copyright $\odot 2019$ by authors, all rights reserved. Authors agree that this article remains permanently open access under the terms of the Creative Commons Attribution License 4.0 International License

\begin{abstract}
Currently, we study, work and build social relationships and economies by employing information technology. However there is a question for people who are interested in supporting and developing education for people with disabilities: What is the impact of information technology on the lives of visually impaired people? The answer to this question has been raised to varying degrees by countries and communities that pay close attention to disability issues and give them considerable attention. Interest from societies and countries is, of course, conditioned by political, economic, and social factors that can make the needs of people with a type of welfare for some governments and communities. In this paper, a new method is introduced for developing websites for visually impaired people by employing Braille codes and the HTML language to provide audio material via the Internet following the use of specialized web pages with pre-selected curricula to support the training of visually impaired people.
\end{abstract}

Keywords Braille, Low Vision, Specialty Web, Visually Impaired

\section{Introduction}

Technology is an essential factor in altering people's lives and increasing their well-being. Modern technologies are often designed for healthy people, while the number of people with disabilities and especially visually impaired people is significant. $4.5 \%$ of children belong to the category of people with disabilities throughout the world [2]. In France, approximately 100,000 people have or will have vision problems out of 750,000 annual births [3].

With such a large number of people with disabilities, researchers have presented several methods to facilitate teaching visually impaired people to reduce the differences between the educational opportunities offered to visually impaired people and their peers, the most important of which is the voice. However, this method cannot be employed in noisy public places and also to evaluate the blind online, as most speech recognition applications are not accurate enough and require a quiet place to insert text [1] [3].

In the field of education, blind or visually impaired students should have the same access as sighted students to all standards, curricula, and education to achieve the necessary levels of literacy and also high academic expectations and to become productive citizens. [3]

This paper provides a method for developing educational websites to provide more educational opportunities for visually impaired students by utilizing the Internet to produce general or academic sounds to facilitate the learning process and research concepts to find techniques for supporting the education of impaired people through website development, which provides links to an electronic audio library containing books, articles, lectures and other items in audio format based on their age. This library is processed by visually impaired people trained in practicing Braille [5] [6] [7].

\section{Proposed E-Learning Method for Visually Impaired and Blind Students}

E-learning contributes to enhancing the quality of life of students [8]. Despite many attempts to develop e-learning platforms, many of these platforms are not practical for people with impaired vision; it is important to discuss the problems of applying e-learning technologies faced by students with impaired eyesight and also to understand that many of these platforms which are ineffective for people with impaired sight [9].

The Braille e-mail possesses a frequency of errors, and this issue leads to their limited application in an Internet search engine to obtain the required results, or conduct 
online tests in a published study.

The number of errors when entering sentences. The overall error rate was lower for the BrailleEnter keyboard (average $=14.12)$ compared to SingleTapBraille (average $=25.95)[1]$.

Therefore, the researcher proposes to prepare applications to support the learning process of visually impaired people by employing the Internet to support education or carry out tests with no design errors to ensure high quality. Several elements are considered to accomplish this task:

1. Create an index with Braille code, including the web page number and theme sequence.

A project for Webhurst and a user manual using Braille code are presented, as shown in Figure 1, using Braille characters that provide the visually impaired people access to primary, secondary, and higher education, especially in the humanities, which illustrates symbols and directions; for instance, audio files in the humanities, which can be applied to study international music by visually impaired people in musical institutions $[10 ; 16]$.

A visually impaired person clicks the button corresponding to the index on the cover of the screen and then returns to the index to pick a file from the desired topic from the list, for example, music, as presented in Figure 2, which is sent to the cover of the screen to display the same code.

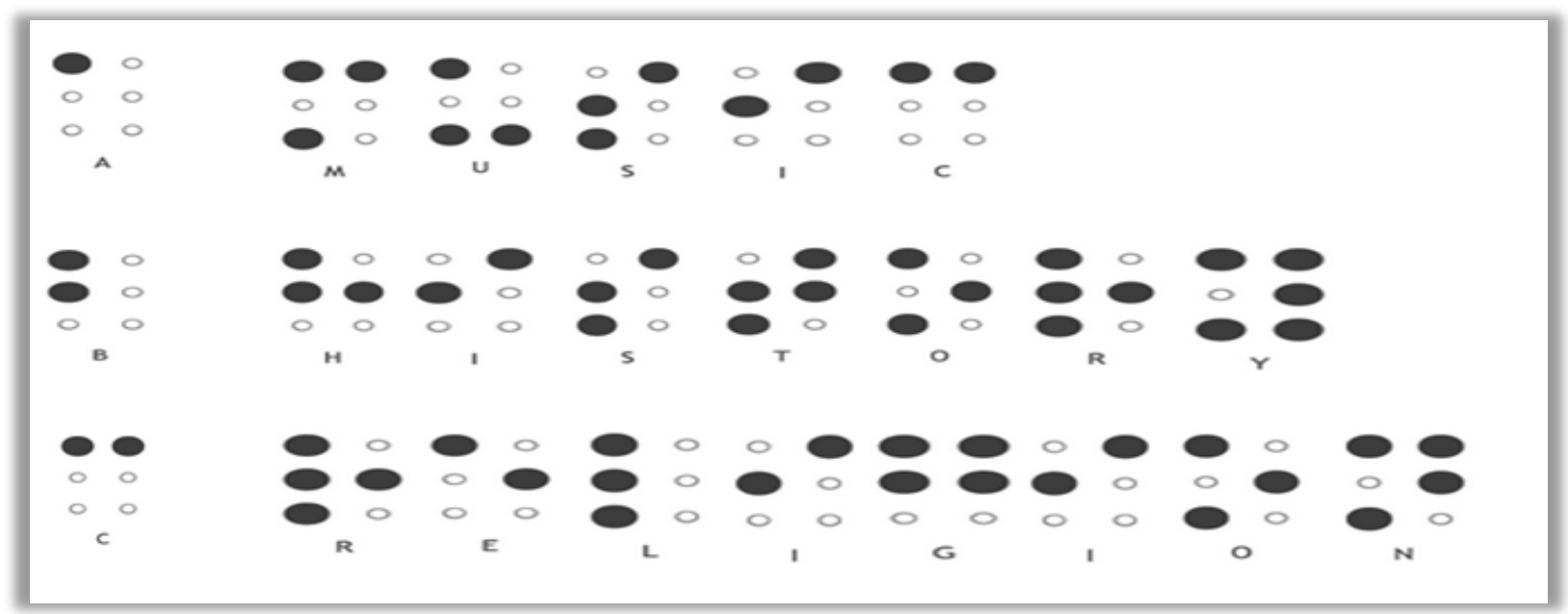

Figure 1. Braille codes to project for Webhurst and a user manual

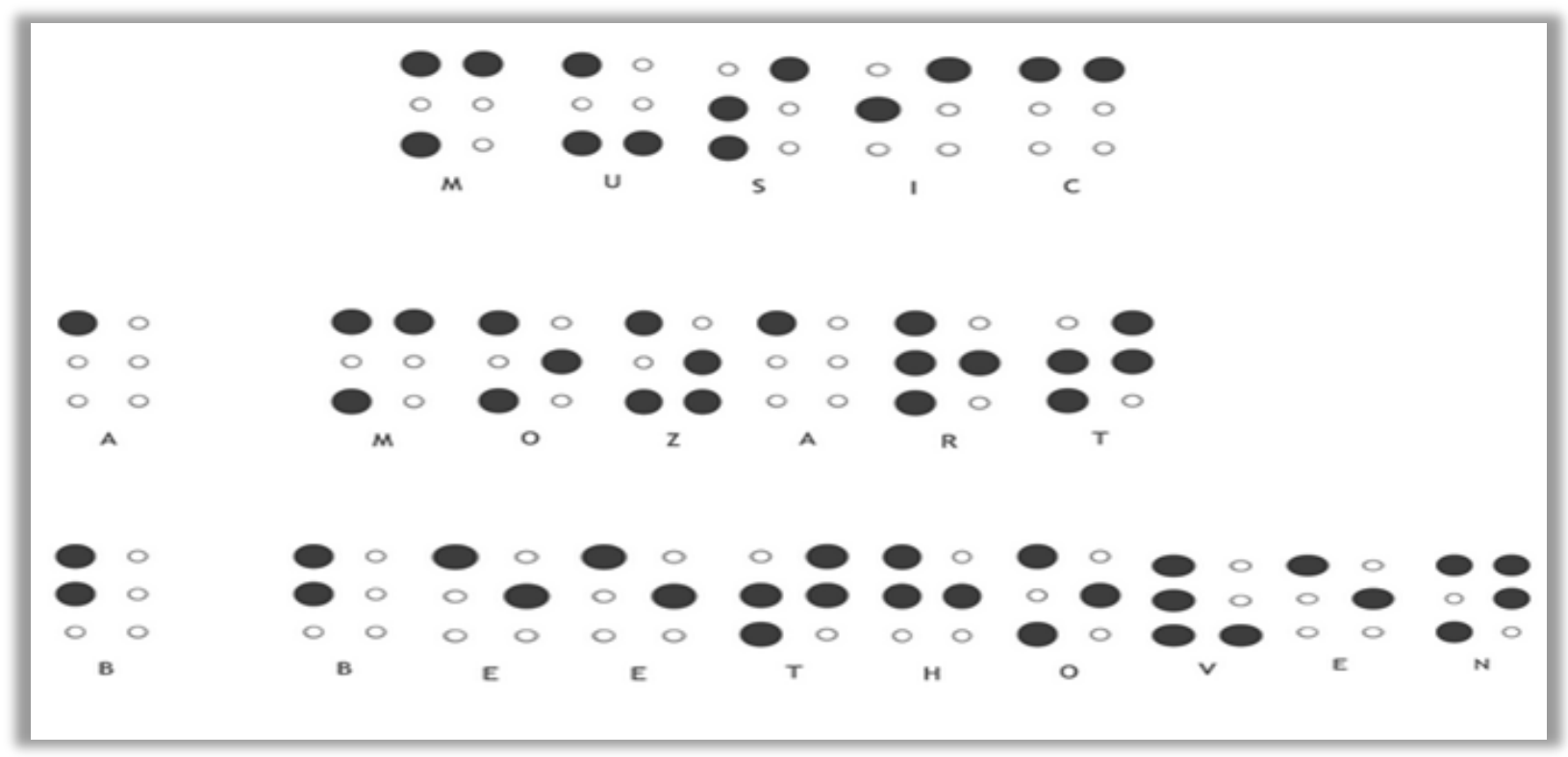

Figure 2. Braille codes to file transport 
1. Design web pages, according to the Braille index prepared in step 1 with Figure 1 and Figure 2.

Web pages should be designed in a way that is completely compatible with the printable characters in the index for the ideal usage of the site, in which Braille symbols symbolize certain pages and buttons that reach the user.

2. Create a screen cover, so that people with visual impairments can choose the appropriate button on the installed screen cover using flexible buttons printed in Braille (as in the index) and read by touch, the material used on the screen cover should be as flexible as silicon [8] with a sensor located under each button. The rest of the screen should be locked and not affected by touch, as shown in Figure 3. In this figure, the circles are buttons and represent a dark area that is not affected by the sensor. Furthermore, the size of the screen corresponds to the size of the screen used.

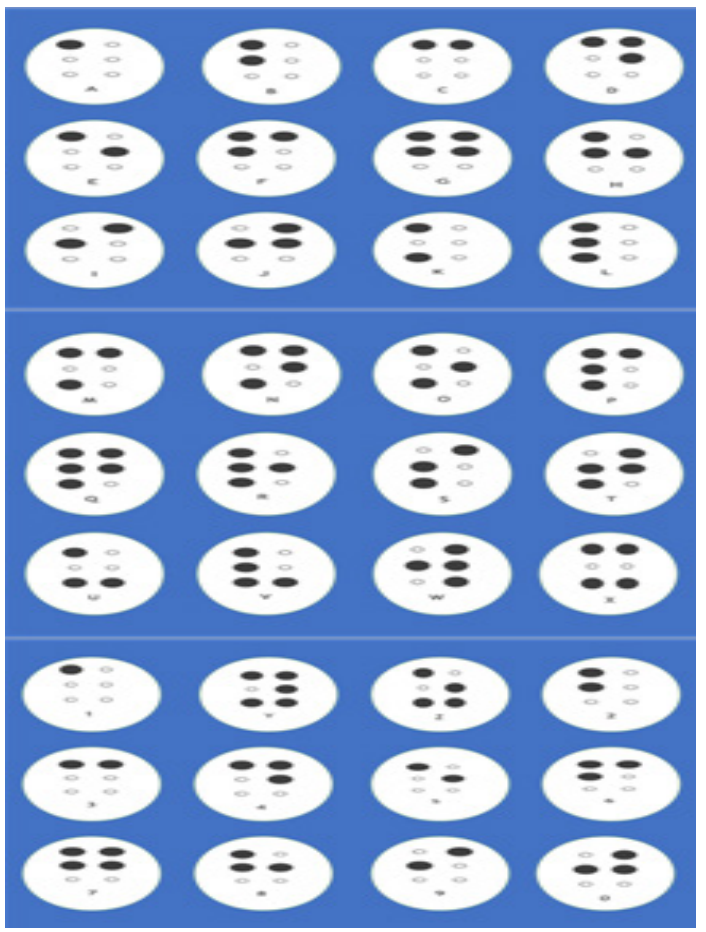

Figure 3. Locked and unaffected bottoms

1. How does this method work?

First, users select the subject in the index and pass their finger to the corresponding symbol in the index. Then, users touch the screen cover keys to find the appropriate button for the subject code in the index. After searching for the desired button, they click this button. This page also contains several sections corresponding to the keys in the index.

Users return to the subject page in the paper index to find the header of the file they want to listen to and the key that represents it on the web page and select the button that opens the file. Therefore, an audio website is required.

Figure 4 presents the steps of this method to access the audio material employing the following tools:

1. Catalogue (Braille Catalo)

2. Screen cover (for Braille)

3. Special network for the use of visual irregularities following the Braille cover design.

4. The educational institution and the programmer need to organize the audio files on the website in order that the selection of the necessary audio files is in accordance with the educational programs and ensuring that they are placed on the web page according to their order in the index.

5. It is also necessary to train and prepare visually impaired students to work with the Braille index that corresponds to the page number in the application, the sequence of audio files in the index and the sequence of buttons on the cover of the screen.

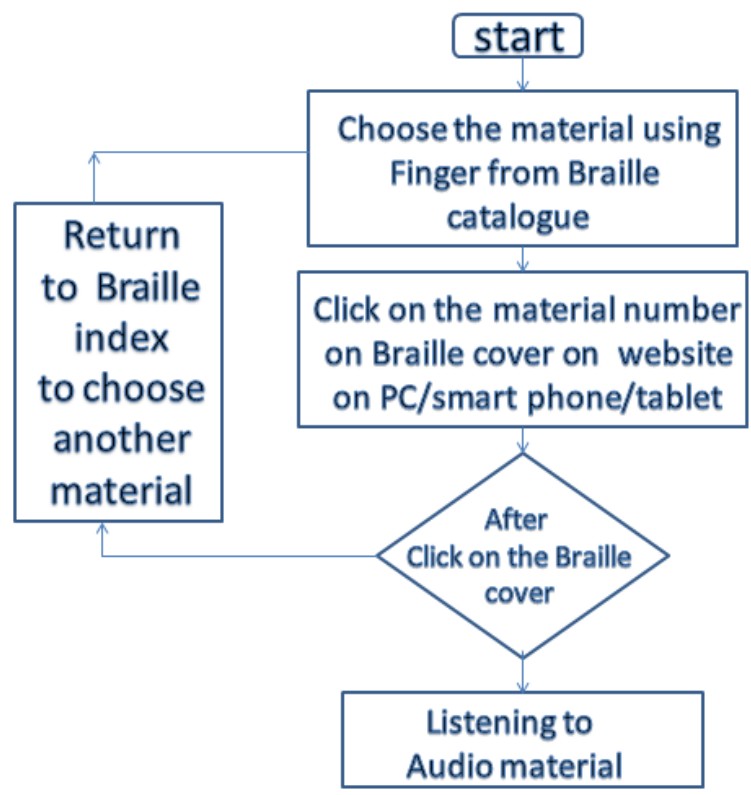

Figure 4. Follow chart to train visually impaired students

Figure 5 indicates the order of operation, which begins with a paper index and pressure on the buttons on the cover of the screen, and then, users open the web page and return to the index to pick a file for a specific object. Finally, they click on the screen cover again to access the audio file through the Internet. 


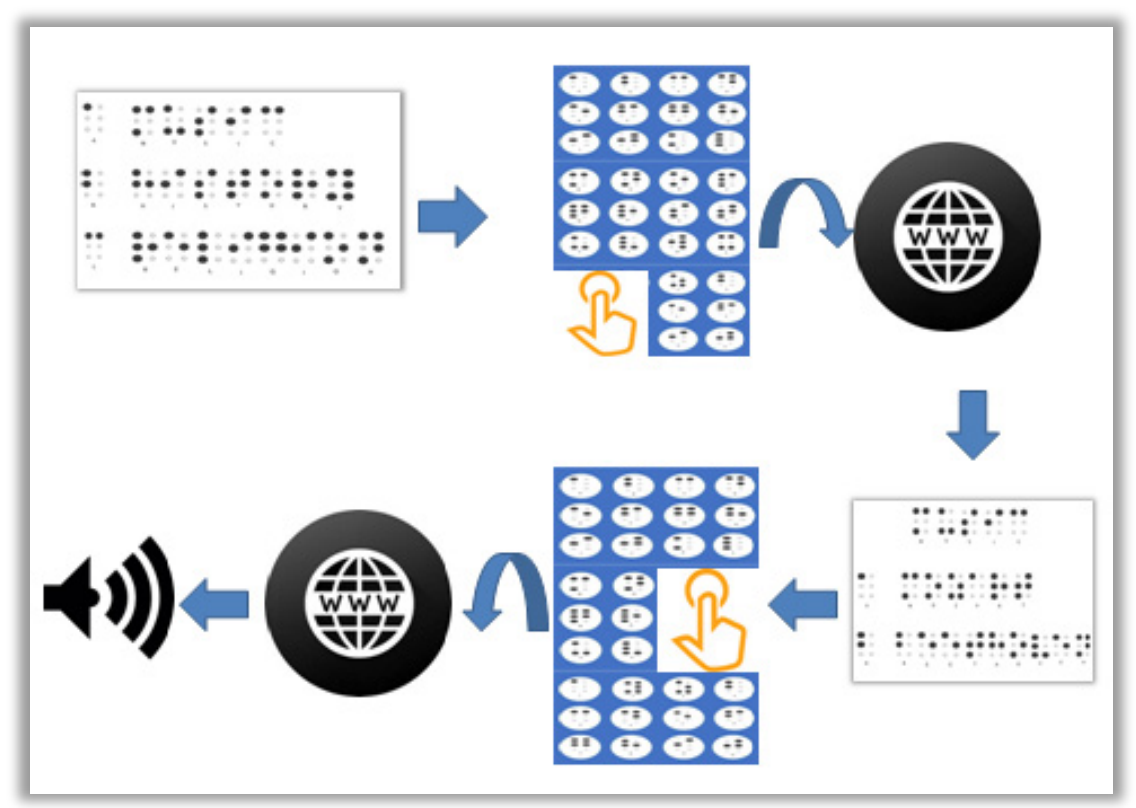

Figure 5. Order of operation

Note:

YouTube Explorer can be employed to download the audio files used on the website. The free website to publish videos can be utilized by this website to create a channel for lessons and audio lectures, from which audio files can be downloaded. The availability to the website is free, see Figure 6.

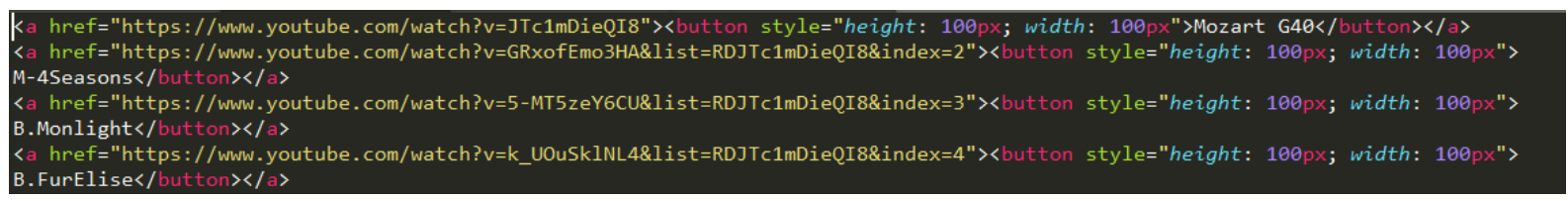

Figure 6. Buttons using HTML.

Note: One of the buttons is assigned to provide access to the website.

The Braille code is practiced in English, but the Braille code of any language can be used [10] [11] [12].

\section{TEXT-TO-SPEECH (TTS)}

The purpose of a text-to-speech (TTS) system is to generate speech from a provided input text [13]. The users know what type of page they are using to avoid possible errors due to visual impairment by simultaneously pressing the buttons of specific pages and the topics for each web page by employing text-to-speech (TTS) [14; 18] technology from GOOGLE, JAVASCRIPT or others to recognize each page via automatic voice recognition.

TTS is an automatic font conversion application that utilizes digital text to synthesize a human voice. This promising technology will be a key part of supporting people with visual disabilities in the future, despite the limited support for several languages, including Arabic [15; 17].

Figure 7 presents the code used to obtain the audio identifier for a web page by pressing a specific button, which allows visually impaired visitors to recognize the content of the page.

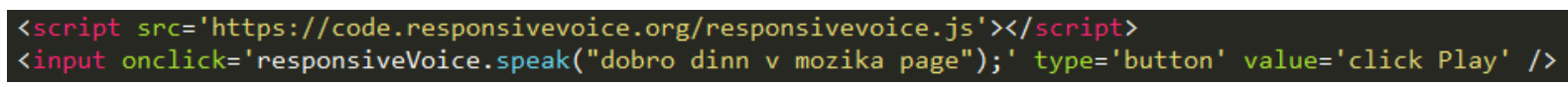

Figure 7. The code to obtain the audio identifier

Figure 8 shows the code used to obtain automatic voice recognition from Google, which also allows visually impaired visitors to recognize the page content. 
The initial challenging is expected for people with impaired vision to understand this method, and they may suffer when working with a paper index written using Braille code. Additionally, it is difficult to understand the electronic application, and Braille keyboard applied on the cover of a computer. However, continuous training with the guidance of an expert will facilitate the process, and visually impaired people will become experts in processing Braille code in the index and using the cover of Braille keyboards on a computer screen or a smartphone screen.

\section{Conclusions}

The proposed method provides people with visual impairments with the means of using information technology and enhancing their use of Internet services, especially in the learning process. The proposed method provides new support to the process of teaching people with visual disabilities and opens up new opportunities for expanding the educational process of learning, as well as public culture.

\section{Acknowledgements}

The work is performed according to the Russian Government Program of Competitive Growth of Kazan Federal University.

\section{REFERENCES}

[1] Biography of Louis Braille and Invention of the Braille Alphabet Survey of Ophthalmology, 54(1), JanuaryFebruary 2009, Pages 142-149: Javier Jiménez, Jesús Olea, Jesús Torres, Inmaculada Alonso, Dirk Harder, Konstanze Fischer

[2] BrailleEnter: A Touch Screen Braille Text Entry Method for the Blind Mrim Alnfiaia, Srinivas Sampalli, Faculty of Computer Science, Dalhousie University, Halifax, B3H 1W5, Canada The 8th International Conference on Ambient Systems, Networks and Technologies (ANT 2017)

[3] Fabrice Maurel et al. (2012). Procedia Computer Science, 14, 319-329.

[4] Gildas Brégain: Colonialism and disability: The situation of blind people in colonised Algeria: Laboratoire IRIS, EHESS, 190-198, avenue de France, 75244 Paris cedex 13, France, et également disponible sur www.em-consulte.com

[5] Kelly, H. F. A., Ponton, M. K., Rovai, A. P. (2007). A Comparison of Student Evaluations of Teaching between Online and Face-To-Face. Courses", Internet and Higher Education, 89-101.

[6] Lawrence R. (2015). Smith, Chairman: The Braille Authority of North America: MUSIC BRAILLE CODE.
[7] Liliya, A. Valeeva:The Current State of Special Needs Education in Russia:Inclusive Policies and Practices/Kazan (Volga Region) Federal University, Institute of Economics and Finance, Butlerova str, no.4, 420012, Kazan, Russia.

[8] Maryland Common Core State Curriculum Frameworks for Braille: English/Language Arts/Maryland State Department of Education (2012)

[9] Nilufer Yurtaya, Yuksel Yurtaya, M. Fatih Adaka: An Education Portal for Visually Impaired: a Sakarya University, Faculty of Computer and Information Sciences 54187, Sakarya, Turkey.

[10] Ramli, I., Jamil, N., Seman, N., \& Ardi, N. (2015). An improved syllabification for a better Malay language text-to-speech synthesis (TTS). Procedia Computer Science, 76, 417-424.

[11] Reddy, V. R., Rao K. S. (2012). Intonation Modeling Using Linguistic, Production and Prosodic Constraints for Syllable based TTS Systems. ICMOC, Procedia Engineering, 38, 2772-2783.

[12] Roberto Neto, Nuno Fonseca: Camera Reading For Blind People/ HCIST 2014 - International Conference on Health and Social Care Information Systems and Technologies, Procedia Technology, 16 (2014), 1200 - 1209.

[13] Saad, D. (2010). Al-Shamma, Sami Fathi: Arabic Braille Recognition and Transcription into Text and Voice/2010 5th Cairo International Biomedical Engineering Conference, Cairo, Egypt, December 16-18.

[14] Sir Clutha, Mackenzie Chairman, World Braille Council:World Braille Usage 1953, UNESCO, Paris, France.

[15] UNESCO (1990). World braille usage. Washington, D.C., U.S.A.: National Library Service for the Blind Physically Handicapped, Library of Congress.

[16] Ulandari, L., Amry, Z., \& Saragih, S. (2019). Development of Learning Materials Based on Realistic Mathematics Education Approach to Improve Students' Mathematical Problem Solving Ability and Self-Efficacy. International Electronic Journal of Mathematics Education, 14(2), 375-383. https://doi.org/10.29333/iejme/5721.

[17] Zhatkin, D. (2018). Russian literary-critical reception of Burns at turning of the XIX-XX centuries. Opción, 34(85-2), 277-300.

[18] Yazdekhasti, A., Erfan, N., \& Nazari, N. (2015) Investigating the Relationship between Spiritual Intelligence and Social Adaptation among Girl High School Students in Shahreza City. UCT Journal of Social Sciences and Humanities Research, 3(1), 20-23. 